\title{
Delineating Mechanisms of Dissociation for Isomeric Heparin Disaccharides Using Isotope Labeling and Ion Trap Tandem Mass Spectrometry
}

\author{
Ola M. Saad and Julie A. Leary \\ Department of Chemistry, University of California at Berkeley, Berkeley, California, USA
}

\begin{abstract}
Heparin and heparan sulfate (HS) glycosaminoglycans have been identified as important players in many physiological as well as pathophysiological settings. A better understanding of the biosynthesis and structure of these molecules is critical for further elucidation of their biological function. We have demonstrated the successful use of negative electrospray ionization tandem mass spectrometry in the differentiation of all twelve standard heparinbuilding blocks, including the potentially important $N$-unsubstituted disaccharides. Collision induced dissociation of each of the isomeric disaccharides provided unique product ion spectra, useful for identification and quantification of the relative amounts of each isomer present. In the research presented herein, isotopic labeling studies using ${ }^{18} \mathrm{O}$ and ${ }^{2} \mathrm{H}$ were used to determine the origins of each of the neutral losses observed in the product ion spectra, and mechanisms of dissociation consistent with the observed data were postulated. The general mechanisms postulated were for the generation of $\mathrm{B}, \mathrm{Y}$, and $\mathrm{Z}$ ions formed from glycosidic cleavages, as well as $\mathrm{A}$ and $\mathrm{X}$ ions formed from cross-ring cleavages. The eight isomeric heparin disaccharides all underwent cross-ring cleavage to form ${ }^{0,2} \mathrm{X}_{1}$ and ${ }^{0,2} \mathrm{~A}_{2}$ ions, and further experiments suggest that the mechanisms of formation of these ions are through a charge-remote process. The tandem mass spectrometry data presented herein also provide a foundation for further developments towards a practical analysis tool for the structural elucidation of larger, biologically important heparin/HS oligosaccharides by using mass spectrometry. (J Am Soc Mass Spectrom 2004, 15, 1274-1286) (c) 2004 American Society for Mass Spectrometry
\end{abstract}

$\mathrm{H}$ eparin and heparan sulfate (HS) glycosaminoglycans (GAGs) have been implicated in a host of biological functions including blood coagulation, inflammatory processes, cell-cell and cellmatrix interactions, as well as cell growth and differentiation [1]. Although heparin has been used clinically as an anticoagulant for decades, and the closely related species, heparan sulfate has been identified as a key player with many biological roles, the absolute structures responsible for the various attributed functions are complex and have only recently been deciphered in a few specific cases. To better understand their biological roles in physiological as well as pathophysiological settings, it is necessary to gain a better understanding about the structure of heparin/HS at the molecular level.

Heparin/HS polysaccharides consist of a repeating disaccharide unit of $[\operatorname{HexA} \beta(1,4) \mathrm{GlcN} \alpha(1,4)]_{\mathrm{n}}$. The hex-

Published online July 17, 2004

Address reprint requests to Dr. J. A. Leary, Department of Chemistry, University of California, 410 Latimer Hall, Berkeley, CA 94720-1460, USA.

E-mail: leary@socrates.berkeley.edu uronic acid (HexA) residue can be either L-iduronic acid (IdoA) or D-glucuronic acid (GlcA) depending on the stereochemistry of the C5 carboxylic acid group, and may be sulfated at the $\mathrm{C} 2$ position. In addition, the glucosamine units may be $\mathrm{N}$-acetylated (GlcNAc), $\mathrm{N}$ sulfated (GlcNS) or $N$-unsubstituted (GlcN), and can be further differentially sulfated at the C3 and C6 positions. Structural studies of heparin and HS have indicated differences between the two, such as the predominance of the trisulfated disaccharide (Ido2S-GlcNS6S) in heparin and of the unsulfated disaccharide (GlcAGlcNAc) in heparan sulfate [2]. Other disaccharide structures exist in lower amounts. The structures of 12 known constituent heparin disaccharides, and the abbreviations used for each, are shown in Figure 1. Included in this series are the basic disaccharides with the unsubstituted amino group on the glucosamine residue (IH, IIH, IIIH, and IVH), which may play an important role in mediating interactions of heparin with its protein partners. For example, recent studies by Varki et al. have shown that HS oligosaccharides, which can bind to L- and P-selectins involved in the inflam- 
matory response, are enriched with these unsubstituted amino groups on the GAG chains $[3,4]$.

With the advent of improved isolation procedures for heparin/HS and the development of new analytical methods for sequence analysis, these once elusive biopolymers are slowly succumbing to structural analysis and further correlation of that structure to its related biological function. Whereas mass spectrometry (MS) has become well-established as a tool for protein analysis, only recently has the use of tandem mass spectrometry for the sequencing of heparin/HS and other GAGs been explored [5-11]. The main advantages of MS, notably, are its sensitivity, accuracy and speed. Whereas NMR can give a wealth of information, and is the only technique that has the potential for complete structural characterization of a carbohydrate, with little assistance from other methods, it requires that a sufficient amount of relatively pure sample is available [12]. Therefore, it is advantageous to explore the extent that MS can complement and further advance the current analysis of carbohydrates, as it has proteins.

In previous work from our laboratory we have applied MS to the determination of heparin/HS disaccharide composition for eight possible disaccharides [13]. To substantiate the use of MS for the continued study of these polysaccharides it is required that we establish the ability of the technique to identify and differentiate all of the isomeric species among the heparin disaccharides. Furthermore, beyond demonstrating that isomeric identification information can be obtained by using MS, a fundamental understanding of the possible mechanisms of dissociation is also necessary in order to further apply some of these methodologies to the sequencing of larger heparin/HS oligosaccharides of biological significance. Our laboratory is interested in the application of these data towards the complete sequencing of heparin/HS oligosaccharides by using a combination of (1) direct $\mathrm{MS}^{n}$ analysis of the GAG and (2) complete enzymatic degradation, followed by disaccharide composition analysis by ESI-MS and $\mathrm{MS}^{n}$. In order to analyze these larger, more complex glycosaminoglycans it is of interest to first determine the system for differentiating all 12 of the constituent disaccharides of heparin.

Of the 12 heparin disaccharides presented herein, eight are isomeric with at least one other disaccharide species and are differentiated by their $\mathrm{MS}^{2}$ spectra. A combination of the disaccharides' $\mathrm{MS}^{2}$ and $\mathrm{MS}^{3}$ spectra were used to confirm assignments of all dissociation products from the original collision induced dissociation (CID) spectrum of each disaccharide. We have also used ${ }^{2} \mathrm{H}$ and ${ }^{18} \mathrm{O}$-labeling studies to assist in identifying the origin of the neutral molecule lost, and have postulated mechanisms of dissociation consistent with the observed data to explain each of these losses.

These tandem mass spectrometry data are also being used in combination with a method previously established, but now modified and extended, in order to include the identification and quantification of all 12 heparin disaccharides produced upon an exhaustive enzymatic digestion of heparin/HS. This work, however, will be the subject of another paper, with its application towards the sequencing of larger heparin oligosaccharides.

\section{Experimental}

\section{Reagents}

The following heparin disaccharide standards, $\Delta U A$ GlcNAc (IVA), $\Delta$ UA2S-GlcNAc (IIIA), $\Delta$ UA-GlcNAc6S (IIA), $\Delta \mathrm{UA}-\mathrm{GlcNS}$ (IVS), $\Delta \mathrm{UA2S}-\mathrm{GlcNAc6S}$ (IA), $\Delta$ UA2S-GlcNS (IIIS), $\Delta$ UA-GlcNS6S (IIS), $\Delta$ UA2SGlcNS6S (IS), as well as N-acetyllactosamine and Nacetyllactosamine $\beta$-ethyl glycoside were obtained from Calbiochem (La Jolla, CA). Chondroitin disaccharide, 2-acetamido-2-deoxy-3-O-( $\beta$-D-gluco-4-enepyranosyluronic acid)-6-O-sulfo-D-galactose ( $\Delta$ UA-GalNAc6S), and heparin disaccharides, $\Delta \mathrm{UA2S}-\mathrm{GlcN6S}$ (IH), $\Delta \mathrm{UA}$ GlcN6S (IIH), $\Delta \mathrm{UA2S}-\mathrm{GlcN}(\mathrm{IIIH})$ and $\Delta \mathrm{UA}-\mathrm{GlcN}$ (IVH) were purchased from Sigma Chemical Co. Deuterium oxide and methanol- $\mathrm{d}_{4}$ were obtained from Aldrich and ${ }^{18} \mathrm{O}$-water was from Cambridge Isotope Laboratories (Cambridge, MA). Solvents used were of HPLC grade and purchased from Fisher (Santa Clara, CA). Heparin disaccharide stock solutions were prepared at concentrations of $2 \mathrm{mM}$ on the basis of their absorbance at $232 \mathrm{~nm}$ in $0.03 \mathrm{M} \mathrm{HCl}\left(\varepsilon_{232}=5500 \mathrm{M}^{-1}\right.$ $\mathrm{cm}^{-1}$ ) [14].

\section{Isotopically Labeled Products}

For the ${ }^{18} \mathrm{O}$-labeling experiments, a $5 \mu \mathrm{L}$ aliquot $(10$ nmol) of each disaccharide stock solution ( $2 \mathrm{mM}$ ) was heated at $60{ }^{\circ} \mathrm{C}$ in $\mathrm{H}_{2}^{18} \mathrm{O}(45 \mu \mathrm{L})$ overnight until complete exchange of the anomeric hydroxyl group with the ${ }^{18} \mathrm{O}$ was obtained. The reaction solution was then diluted with $50 \mu \mathrm{L}$ of $\mathrm{MeOH}$ to a final concentration of $100 \mathrm{pmol} / \mu \mathrm{L}$. Another aliquot of each disaccharide (5 $\mu \mathrm{L}, 10 \mathrm{nmol}$ ) was heated for $45 \mathrm{~min}$ at $60{ }^{\circ} \mathrm{C}$ in ${ }^{2} \mathrm{H}_{2} \mathrm{O}$ to replace all exchangeable hydrogens. The final solution was then diluted with $50 \mu \mathrm{L}$ of $\mathrm{MeO}^{2} \mathrm{H}$. All samples were then analyzed by electrospray ionization mass spectrometry (ESI-MS ${ }^{n}$ ) without purification.

\section{Mass Spectrometry}

All samples were run using electrospray ionization on a quadrupole ion trap mass spectrometer (ThermoFinnigan LCQ, San Jose, CA). The data acquisition software used was Xcalibur, Version 1.2. Disaccharide standards were sprayed at a concentration of $100 \mathrm{pmol} / \mu \mathrm{L}$, from a 1:1 $\mathrm{MeOH} / \mathrm{H}_{2} \mathrm{O}$ solution. Samples were introduced by direct infusion at $3 \mu \mathrm{L} / \mathrm{min}$ using a syringe pump. Spectra were obtained in negative ion mode using a spray voltage at $3.8 \mathrm{kV}$, and a capillary temperature of $200{ }^{\circ} \mathrm{C}$ for all experiments, unless otherwise noted in the figure legend. The automatic gain control was set to 


\begin{tabular}{llllll} 
& \\
& & & & & \\
\hline
\end{tabular}

Figure 1. The chemical structures of twelve heparin/heparan sulfate disaccharides (A-L).

$1 \times 10^{7}$ counts for full scan MS and to $2 \times 10^{7}$ for MS ${ }^{\mathrm{n}}$ experiments in order to keep space charge effects to a minimum. Optimization of the signal from the precursor ion of interest was accomplished by using the automatic tune feature on the instrument. For $\mathrm{MS}^{2}$ experiments, the mass range scanned was $m / z$ 100-500. Selection of each precursor ion was achieved using an isolation width of $1 \mathrm{Da}$, and the ion was activated at $0.6-0.8 \mathrm{~V}$ (29\% normalized collision energy) for $100 \mathrm{~ms}$, and the $q_{z}$ value was maintained at 0.25 . Each mass spectrum obtained consists of an average of 20 scans.

\section{Results and Discussion}

\section{ESI-MS/MS ${ }^{n}$ Product Ion Mass Spectra of Heparin Isomeric Disaccharides}

There are at least twelve disaccharide structures with varying degrees of sulfation that have been identified as constituents of heparin/HS. The structures of those disaccharides are shown in Figure 1. It has been previously shown that using ESI-MS, with the addition of ammonium hydroxide to reduce sodium adduction, results in no sulfate loss for each of the eight disaccharides in the $\mathrm{N}$-sulfated and $\mathrm{N}$-acetylated disaccharide series [13]. This remains true with the addition of the four $\mathrm{N}$-unsubstituted disaccharides to the group $(\mathrm{H}$

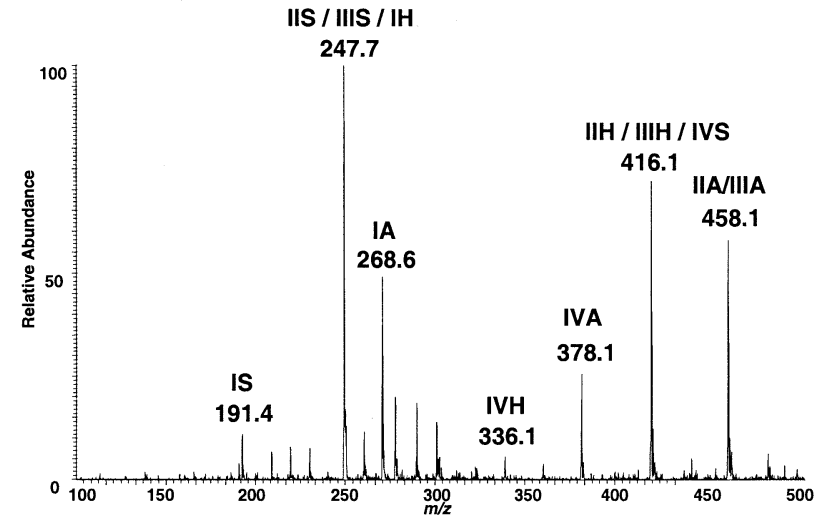

Figure 2. $\mathrm{MS}^{1}$ of a mixture of all 12 heparin/HS disaccharides at $20 \mathrm{pmol} / \mu \mathrm{L}$.

series). Under the spray conditions utilized, the most abundant ion in each case was the molecular ion whose charge state, $z$, equals the number of sulfates on the disaccharide (Figure 1). When a mixture of the 12 heparin disaccharides is subjected to electrospray ionization, a mass spectrum such as that shown in Figure 2 is obtained. Four of the 12 disaccharides, IA, IVA, IS, and IVH are distinguishable in this full scan MS directly by their mass-to-charge ratios. However, the three sets of isomers comprised of the other eight disaccharides, IIA/IIIA, IIS/IIIS/IH, and IIH/IIIH/IVS could not be directly differentiated from the MS ${ }^{1}$ spectrum, and were therefore the subject of further study. Other ions in the spectrum, which are not annotated, arise from different charge states of the disaccharides or from sodiation.

The monosulfated and acetylated disaccharides, IIA and IIIA have a molecular ion, $[\mathrm{M}-\mathrm{H}]^{-}$at $\mathrm{m} / \mathrm{z}$ 458.1, and the disulfated disaccharides, IIS, IIIS and IH, are observed at $m / z 247.7,[\mathrm{M}-2 \mathrm{H}]^{2-}$. The monosulfated disaccharides, IVS, IIH, and IIIH are detected at $\mathrm{m} / \mathrm{z}$ 416.1, $[\mathrm{M}-\mathrm{H}]^{-}$. Herein we show the acquired MS/MS data, under identical conditions for each set of isomers, that was used to differentiate them. $\mathrm{MS}^{2}$ spectra for disaccharides IIA and IIIA are shown in Figure 3a and $\mathrm{b}$, respectively. For disaccharides IIS, IIIS and IH, the $\mathrm{MS}^{2}$ spectra are shown in Figure $4 \mathrm{a}-\mathrm{c}$, and for disaccharides IIH, IIIH and IVS, the $\mathrm{MS}^{2}$ spectra are shown in Figure $5 a-c$.

Three main types of dissociation were observed in the product ion mass spectra: (1) neutral loss of a small molecule $\left(\mathrm{SO}_{3}, \mathrm{H}_{2} \mathrm{O}\right.$ or $\left.\mathrm{CO}_{2}\right)$, (2) glycosidic cleavage, and (3) cross-ring cleavage. Glycosidic and cross-ring cleavages are identified in Figures $3-5$ by using established Domon-Costello nomenclature [15]. We have also used ${ }^{2} \mathrm{H}$ and ${ }^{18} \mathrm{O}$-labeling studies to assist in identifying the neutral molecule lost in all cases. In the first study with ${ }^{2} \mathrm{H}$, all of the exchangeable hydrogens were substituted for ${ }^{2} \mathrm{H}$, and in the second study, the anomeric hydroxyl oxygen was labeled with ${ }^{18} \mathrm{O}$. With these two isotopic labeling experiments we effectively obtained an abundance of information about all of the dissociation products for each of the isomers, and have 

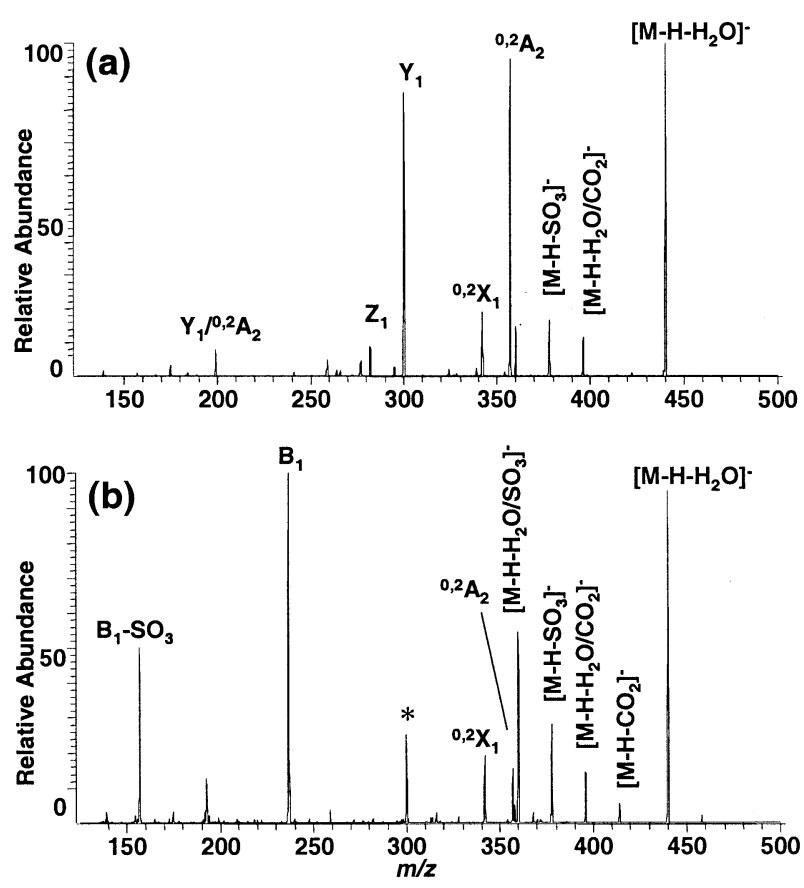

(c)

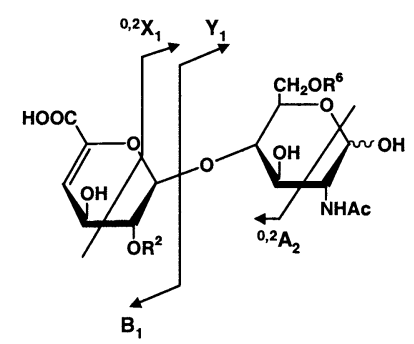

IIA, $\mathrm{R}^{2}=\mathrm{H}, \mathrm{R}^{6}=\mathrm{SO}_{3} \mathrm{H}$

IIIA, $\mathrm{R}^{2}=\mathrm{SO}_{3} \mathrm{H}, \mathrm{R}^{6}=\mathrm{H}$

(d) Comparison of Dissociations for IIA/IIIA

\begin{tabular}{|c|c|c|c|c|c|c|c|c|c|c|c|}
\hline & $-\mathrm{H}_{2} \mathrm{O}$ & $-\mathrm{CO}_{2}$ & $-\mathrm{SO}_{3}$ & $\begin{array}{l}\mathrm{SO}_{\mathrm{H}} \mathrm{O} \\
\mathrm{H}_{2}\end{array}$ & $\begin{array}{l}-\mathrm{CO}_{2}{ }^{\prime} \\
\mathrm{H}_{2} \mathrm{O}\end{array}$ & $B_{1}$ & $\begin{array}{l}\mathrm{B}_{1-}^{-} \\
\mathrm{SO}_{3}\end{array}$ & $Y_{1}$ & $z_{1}$ & ${ }_{0}^{0}{ }^{2} \mathrm{~A}_{2}$ & $0,2 x_{1}$ \\
\hline IIA & $x$ & & $\mathrm{x}$ & $\mathrm{x}$ & $\mathrm{x}$ & & & $\mathrm{x}$ & $x$ & $\mathrm{X}$ & $\mathrm{x}$ \\
\hline IIIA & $x^{*}$ & $\mathrm{x}$ & $x$ & $x$ & $\mathrm{x}$ & $\mathrm{x}$ & $\mathrm{x}$ & & & $x$ & $\mathrm{x}$ \\
\hline
\end{tabular}

Figure 3. $\mathrm{MS}^{2}$ spectra $(\mathrm{m} / \mathrm{z} 458.1 \rightarrow)$ of the two monosulfated, acetylated isomeric disaccharides. (a) $\mathrm{MS}^{2}$ of IIA, $\Delta \mathrm{UA}-\mathrm{GlcNAc6S}$; (b) MS $^{2}$ of IIIA, $\triangle$ UA2S-GlcNAc; (c) structures of disaccharides IIA and IIIA with major product ions indicated; (d) Comparision of dissociations of IIA/IIIA. *At this time, the identity of $\mathrm{m} / \mathrm{z} 300$ in (b) is unknown. Experiments are ongoing to determine its composition.

postulated mechanisms of dissociation consistent with the observed data to explain each of these losses. Those product ions formed via glycosidic and cross-ring cleavages were of most interest because they generated diagnostic ions for each disaccharide, identifying positions of sulfation. The generic mechanisms postulated for the glycosidic cleavages, forming $\mathrm{B}, \mathrm{Y}$, and $\mathrm{Z}$ ions are shown in Schemes 1-3, respectively. Those mechanisms for the two main cross-ring cleavages, to generate the observed ${ }^{0,2} \mathrm{~A}_{2}$ and ${ }^{0,2} \mathrm{X}_{1}$ ions, are shown in Schemes 4 and 5 .
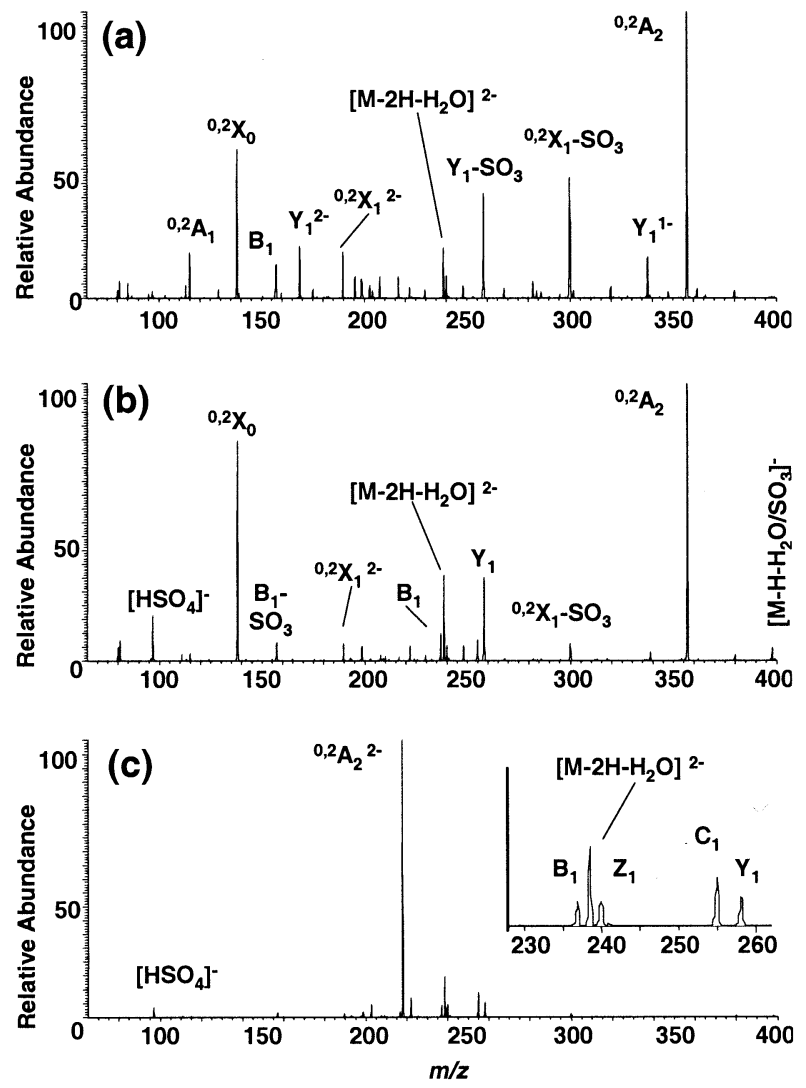

(d)

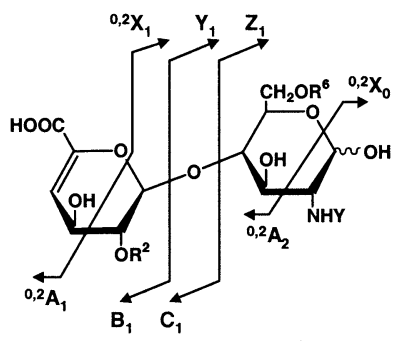

IIS, $\mathrm{R}^{2}=\mathrm{H}, \mathrm{R}^{6}=\mathrm{SO}_{3} \mathrm{H}, \mathrm{Y}=\mathrm{SO}_{3} \mathrm{H}$ IIIS, $R^{2}=\mathrm{SO}_{3} \mathrm{H}, \mathrm{R}^{6}=\mathrm{H}, \mathrm{Y}=\mathrm{SO}_{3} \mathrm{H}$ $\mathrm{IH}, \mathrm{R}^{2}=\mathrm{SO}_{3} \mathrm{H}, \mathrm{R}^{6}=\mathrm{SO}_{3} \mathrm{H}, \mathrm{Y}=\mathrm{H}$

(e) Comparison of Dissociations for IIS / IIIS / IH

\begin{tabular}{|c|c|c|c|c|c|c|c|c|c|c|c|c|c|}
\hline & $\mathrm{HSO}_{4}^{-}$ & $-\mathrm{H}_{2} \mathrm{O}$ & $\begin{array}{c}-\mathrm{SO}_{3} / \\
\mathrm{H}_{2} \mathrm{O}\end{array}$ & $\mathrm{B}_{1}$ & $\begin{array}{l}\mathrm{B}_{1}- \\
\mathrm{SO}_{3}\end{array}$ & $Y_{1}$ & $\begin{array}{l}\mathrm{Y}_{1-}- \\
\mathrm{SO}_{3}\end{array}$ & $\mathrm{C}_{\mathrm{l}}$ & $\mathrm{Z}_{\mathrm{i}}$ & ${ }^{0.2} \mathrm{~A}_{2}$ & ${ }^{0.2} \mathrm{X}_{0}$ & ${ }^{0.2} \mathrm{X}_{1}$ & $\begin{array}{l}{ }^{0,2} \mathrm{X}_{1} \\
-\mathrm{SO}_{3}\end{array}$ \\
\hline IIS & & $\mathrm{x}$ & & $X$ & & $\mathrm{X}$ & $\mathrm{X}$ & & & $X$ & $X$ & $X$ & $x$ \\
\hline IIIS & $X$ & $x$ & $X$ & $\mathrm{X}$ & $\mathrm{X}$ & $x$ & & $X$ & & $\mathrm{X}$ & $X$ & $\mathrm{X}$ & $X$ \\
\hline IH & $X$ & $\mathrm{X}$ & & $\mathrm{X}$ & & $X$ & & $X$ & $\mathrm{X}$ & $\mathrm{X}$ & & & \\
\hline
\end{tabular}

Figure 4. $\mathrm{MS}^{2}$ spectra $(\mathrm{m} / \mathrm{z} 247.7 \rightarrow)$ of the three disulfated isomeric disaccharides. (a) MS ${ }^{2}$ of IIS, $\triangle \mathrm{UA}-\mathrm{GlcNS} 6 \mathrm{~S}$; (b) $\mathrm{MS}^{2}$ of IIIS, $\Delta$ UA2S-GlcNS; (c) MS2 of IH, $\Delta$ UA2S-GlcN6S; (d) structures of disaccharides IIS, IIIS and IH with major product ions indicated; (e) comparison of dissociations of IIS/IIIS/IH.

\section{IIA/IIIA Heparin Disaccharides}

Upon CID of the molecular ion for each of the monosulfated, acetylated disaccharides, IIA and IIIA, the 


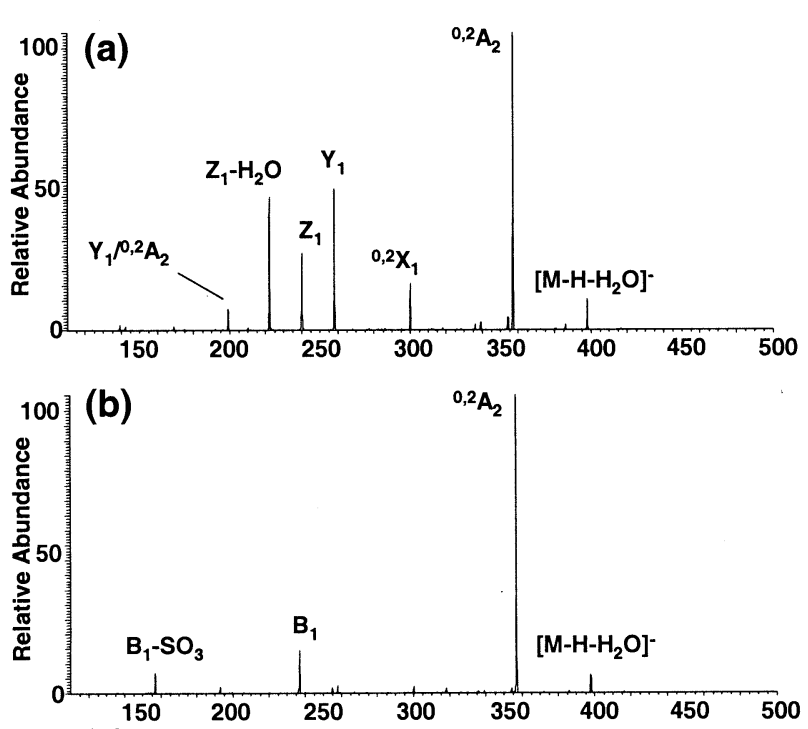

(c)

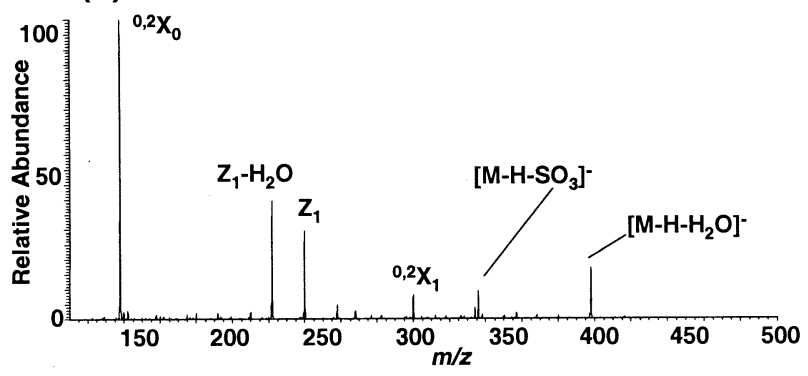

(d)

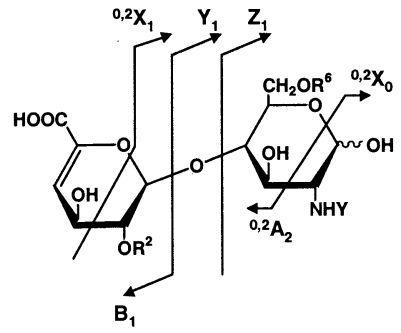

IIH, $\mathrm{R}^{2}=\mathrm{H}, \mathrm{R}^{6}=\mathrm{SO}_{3} \mathrm{H}, \mathrm{Y}=\mathrm{H}$ IIIH, $\mathrm{R}^{2}=\mathrm{SO}_{3} \mathrm{H}, \mathrm{R}^{6}=\mathrm{H}, \mathrm{Y}=\mathrm{H}$ IVS, $R^{2}=H, R^{6}=H, Y=S O_{3} H$

(e) Comparison of Dissociations for IIH / IIIH / IVS

\begin{tabular}{ccccccccccc}
\hline & $-\mathrm{H}_{2} \mathrm{O}$ & $-\mathrm{SO}_{3}$ & $\mathrm{~B}_{1}$ & $\mathrm{BO}_{3}$ & $\mathrm{Y}_{1}$ & $\mathrm{Z}_{1}$ & $\mathrm{H}_{2} \mathrm{O}$ & ${ }^{0,2} \mathrm{~A}_{2}$ & ${ }^{0,2} \mathrm{X}_{0}$ & ${ }^{0,2} \mathrm{X}_{1}$ \\
\hline IIH & $\mathrm{X}$ & & & & $\mathrm{X}$ & $\mathrm{X}$ & $\mathrm{X}$ & $\mathrm{X}$ & & $\mathrm{X}$ \\
IIIH & $\mathrm{X}$ & & $\mathrm{X}$ & $\mathrm{X}$ & & & & $\mathrm{X}$ & & $\mathrm{X}$ \\
IVS & $\mathrm{X}$ & $\mathrm{X}$ & & & & $\mathrm{X}$ & $\mathrm{X}$ & & $\mathrm{X}$ & $\mathrm{X}$ \\
\hline
\end{tabular}

Figure 5. $\mathrm{MS}^{2}$ spectra $(\mathrm{m} / \mathrm{z} 416.1 \rightarrow)$ of the three monosulfated, isomeric disaccharides. (a) $\mathrm{MS}^{2}$ of IIH, $\Delta \mathrm{UA}-\mathrm{GlcN6S}$; (b) $\mathrm{MS}^{2}$ of IIIH, $\Delta$ UA2S-GlcN; (c) MS ${ }^{2}$ of IVS, $\Delta$ UA-GlcNS; (d) structures of disaccharides IIH, IIIH, and IVS with major product ions indicated; (e) comparision of dissociations of IIH/IIIH/IVS.

product ion spectra generated are distinguishable (Figure $3 a$ and $b$ ). The major product ions and their isotopic labeling results are summarized in Figure 3 and Table 1, respectively. Several product ions, such as $m / z 440,396$, 378 , and 360 are common to both isomers, and were generated from the neutral losses of one small molecule or a combination thereof. For example, a predominant product ion is loss of $\mathrm{H}_{2} \mathrm{O}$ at $\mathrm{m} / \mathrm{z} 440$. From ${ }^{18} \mathrm{O}$-labeling it can be determined that this loss is not from the $\mathrm{C} 1$ oxygen on the reducing ring. We postulate that it originates from the $\mathrm{C} 3$ hydroxy group and the $\mathrm{C} 2$ hydrogen on the reducing ring. Subsequent dissociation of this product ion at $m / z 440$, in the case of disaccharide IIA, results in the formation of an ion at $m / z$ 175. If we consider the $\mathrm{m} / \mathrm{z} 175$ to be a deprotonated uronic acid unit, formed by cleavage of the glycosidic bond ( $C_{1}$ ion), then the water loss could not have occurred from the non-reducing ring, otherwise the fragment would be expected at $m / z$ 157. Deuterium-labeling studies (results shown in Table 1) also show that water loss from these disaccharides involves loss of a hydroxyl group and a carbon-bound hydrogen, consistent with our proposed mechanism. This mechanism has also been predicted by theoretical studies of glycopyranosyl disaccharide fragmentation [16], and based on the determination of the relative acidities of the glucopyranosyl hydroxy groups [17].

Other common product ions, which have lost the sulfate group are $\mathrm{m} / \mathrm{z} 378$ and $\mathrm{m} / \mathrm{z} 360$. The ion at $\mathrm{m} / \mathrm{z} 378$ (loss of $80 \mathrm{Da}$ ), was assigned as $\left[\mathrm{M}-\mathrm{H}-\mathrm{SO}_{3}\right]^{-}$, and does not correspond to the loss of $\mathrm{CO}_{2} / 2 \mathrm{H}_{2} \mathrm{O}$. This is based on the deuterium-labeling experiment, which indicates the corresponding product ion is at $\mathrm{m} / \mathrm{z} 384$ and therefore retains all six exchangeable protons from the precursor ion, suggesting that no water loss has likely occurred. In addition, $m / z 360$ likely corresponds to a loss of $\mathrm{SO}_{3} / \mathrm{H}_{2} \mathrm{O}$ and not $\mathrm{CO}_{2} / 3 \mathrm{H}_{2} \mathrm{O}$, again due to several reasons. First, the deuterium-labeling experiment shows that the ion retains four exchangeable protons of the six in the precursor ion, indicating that the loss of three water molecules would be unlikely. Loss of perdeuterated water is not unusual as formation of epoxides with loss of ${ }^{2} \mathrm{H}_{2} \mathrm{O}$ has been previously reported [18]. Additional evidence that the sulfate has been lost comes from collisionally activating the ion at $\mathrm{m} / \mathrm{z}$ 360; the $\mathrm{MS}^{3}$ product ion spectra for both disaccharide IIA and IIIA are identical, which fits with the postulate that the differentiating sulfate has already been lost. Furthermore, in those MS $^{3}$ spectra there is additional evidence indicating that the carboxylate group is still present in the molecule. For example, no loss of sulfate $(-80,81$, or $98 \mathrm{Da})$ is observed from the ion at $\mathrm{m} / \mathrm{z} 360$, whereas a loss of $44 \mathrm{Da}$ is observed, consistent with loss of $\mathrm{CO}_{2}$ at this later stage. A product ion at $\mathrm{m} / \mathrm{z} 157$ is also formed, which corresponds to the $\mathrm{B}_{1}$ ion, retaining the carboxylate group but no sulfate.

In addition to the product ions common to both the IIA/IIIA isomers, there are also several diagnostic ions whose presence and/or abundance is unique to each isomer. Our laboratory has previously shown that this information could be used for identification as well as quantification purposes [13]. For disaccharide IIIA, the 


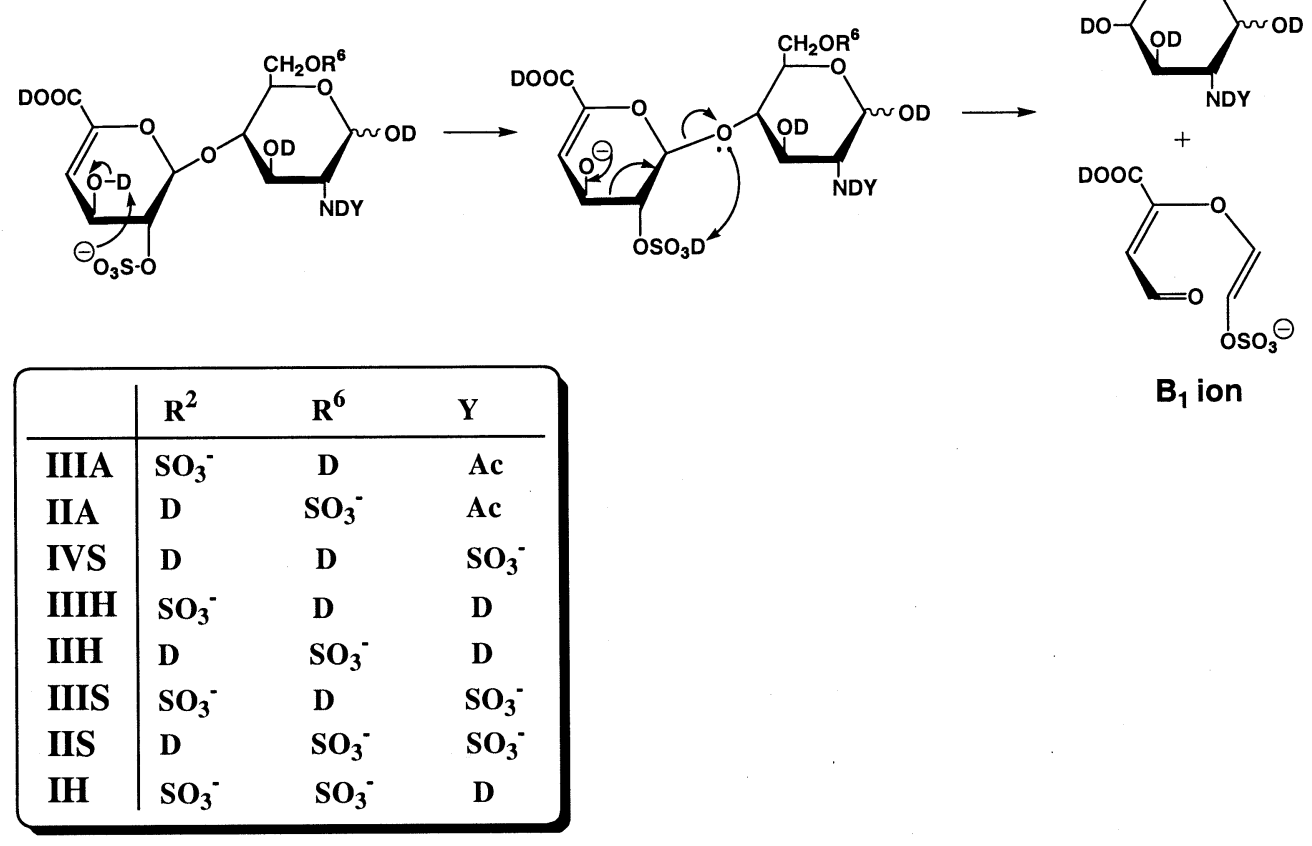

Scheme 1. Dissociation mechanism for formation of $B_{1}$ ions.

presence of a diagnostic ion at $\mathrm{m} / \mathrm{z} 237$, corresponds to the glycosidic cleavage, where charge is retained on the non-reducing end portion of the molecule containing the sulfate group, to form a $B_{1}$ ion. $A$ mechanism showing the formation of the $B_{1}$ ion in this case is shown in Scheme 1. Consistent with the results obtained from the deuterium-labeling experiments conducted, the $B_{1}$ ion retains only one exchangeable proton. In contrast, both isomers IIA and IIIA have a product ion labeled as ${ }^{0,2} \mathrm{~A}_{2}$, at $\mathrm{m} / \mathrm{z} 357$, but with very different ion abundances. This ion derives from an odd mass loss of $101 \mathrm{Da}$, and from labeling studies corresponds to the loss of $\mathrm{C} 1-\mathrm{C} 2$ from the reducing ring and a composition of $\mathrm{C}_{4} \mathrm{H}_{7} \mathrm{NO}_{2}$. The labeling studies and mechanism for the formation of the ${ }^{0,2} \mathrm{~A}_{2}$ product ion for all heparin disaccharides studied will be discussed further on in the text. See Scheme 4 for the proposed mechanism. Similarly, the cross-ring cleavage forming the ${ }^{0,2} X_{1}$ ion is also present for both disaccharides IIA and IIIA and will be discussed later in the context of mechanisms of dissociation that are common to all of the heparin disaccharides.

\section{IIS/IIIS/IH Heparin Disaccharides}

Under the spray conditions utilized, the disulfated disaccharide isomers, IIS, IIIS and IH were detected solely as the doubly charged molecular ion at $\mathrm{m} / \mathrm{z}$ $247.7^{2-}$ (Figure 2). Similar to disaccharides IIA and IIIA these three isomeric disaccharides could also be distinguished by MS/MS, although their product ion spectra were more complex (Figure $4 a-c$ ). Interestingly, the most abundant product ions in all three spectra are those formed by cross-ring cleavages, as opposed to cleavage of the glycosidic bond or loss of a small, neutral molecule. For all three isomers the base peak corresponds to the formation of the ${ }^{0,2} \mathrm{~A}_{2}$ ion. The product ion is at $\mathrm{m} / \mathrm{z} 357$ (mass loss of $138 \mathrm{Da}$ ) for disaccharides IIS and IIIS, which have lost one charge and sulfate group on the 2-amino position of the glucosamine, and at $\mathrm{m} / \mathrm{z} 218.1$ (mass loss of $59 \mathrm{Da}$ ) for disaccharide $\mathrm{IH}$, which remains doubly-charged and still retains both sulfate groups (Figure $4 \mathrm{~d}$ ). Again, the formation of this ${ }^{0,2} \mathrm{~A}_{2}$ ion will be discussed further on, following the proposed mechanism shown in Scheme 4.

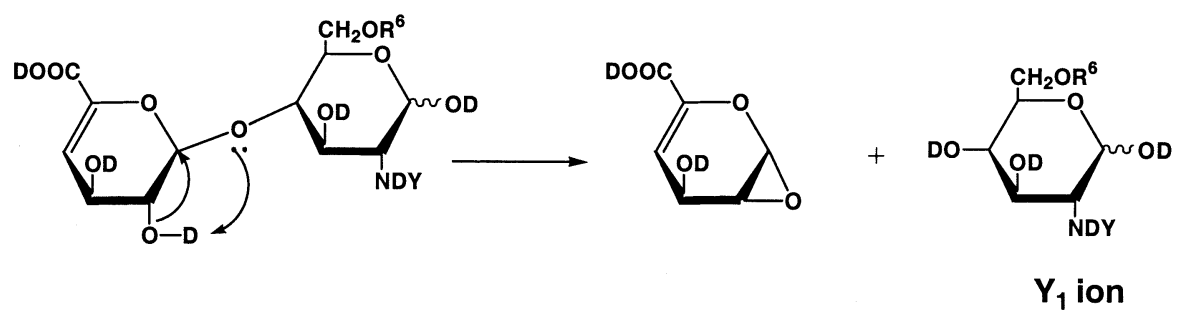

Scheme 2. Dissociation mechanism for formation of $Y_{1}$ ions. 


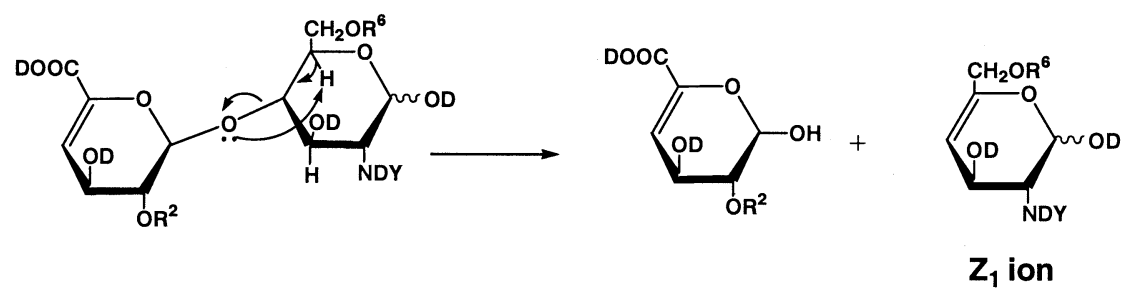

Scheme 3. Dissociation mechanism for formation of $Z_{1}$ ions.

The complementary ${ }^{0,2} X_{0}$ ion is also clearly present for disaccharides IIS and IIIS, as it retains one charge, presumably on the $\mathrm{N}$-sulfate. Other ions corresponding to $\mathrm{B}$ and $\mathrm{Y}$ ions are also present to a lesser extent in each of the spectra for disaccharides IIS, IIIS and IH.

The $\mathrm{MS}^{2}$ spectrum of the molecular ion at $m / z 247.7^{2-}$ for disaccharide IIS (Figure 4a) also shows two abundant fragment ions, which are the result of a glycosidic/ cross-ring cleavage, in addition to the loss of sulfate: $\mathrm{Y}_{1}-\mathrm{SO}_{3}$ at $m / z 258$ and ${ }^{0,2} \mathrm{X}_{1}-\mathrm{SO}_{3}$ at $\mathrm{m} / z$ 300. For the disulfated disaccharide IIS, the positions of sulfation are at the 6-O position of the glucosamine and the 2-amino position (Figure $4 \mathrm{~d}$ ). From the subsequent dissociation of each of these product ions of IIS, at $\mathrm{m} / \mathrm{z} 258$ and at $\mathrm{m} / \mathrm{z}$ 300 , the loss of sulfate could not be localized to either the 2-amino or 6-O positions. There was a predominant ion corresponding to the mass loss of $59 \mathrm{Da}$ (the unsulfated amino-alcohol, 2- amino-ethene-ol), which would indicate that the original $\mathrm{SO}_{3}$ lost had come from the 2-amino position. However, there was also formation of a product ion at $m / z 138$, which corresponds to the sulfated amino-alcohol, or ${ }^{0,2} X_{0}$ ion. Therefore, the most reasonable explanation is that both populations of ions $\left(\mathrm{SO}_{3}\right.$ loss from $2-\mathrm{O}$ or from the $6-\mathrm{O}$ position) contribute to the product ions, $\mathrm{Y}_{1}-\mathrm{SO}_{3}$, at $\mathrm{m} / \mathrm{z} 258$ and ${ }^{0,2} \mathrm{X}_{1}-\mathrm{SO}_{3}$ ion, at $\mathrm{m} / \mathrm{z} 300$.

Of special interest to our laboratory, however, are those ions, which are distinguishing ions for each of the disaccharides and can thus be used for identification and quantification of relative amounts of each isomer in a mixture. For example, the obvious distinction for disaccharide $\mathrm{IH}$ is the predominant ion at $m / z 218\left({ }^{0,2} \mathrm{~A}_{2}\right.$ ion), which is completely absent for disaccharides IIS and IIIS at that mass-to-charge ratio. For disaccharide IIS, the two sulfate groups on the molecule are both on the reducing ring. The glycosidic cleavage of this disaccharide results in the formation of two distinctive ions at $m / z 338^{1-}$ and $168.6^{2-}$, which correspond to the $Y_{1}$ ion, singly and doubly charged, respectively. The mechanism shown in Scheme 2 fits with the labeling data obtained for formation of the $Y_{1}$ ion. For the ion at $m / z 168.6^{2-}$ the $Y_{1}$ ion retains both sulfate groups, and is deprotonated at two sites to give it the 2- charge. If we consider that the most acidic sites on the molecule, the sulfate groups, are deprotonated to start, this is consistent with the ${ }^{2} \mathrm{H}$-labeling experiment data, (Table 2, row 10) where four of the six deuterium atoms on the molecule are retained in the $Y_{1}$ ion and two are lost upon dissociation of the molecular ion. For the ion at $m / z 338^{1-}$, however, the final $Y_{1}$ ion retains both sulfate groups, but is deprotonated at only one site to give it the 1- charge state. For this to be consistent with the ${ }^{2} \mathrm{H}$ labeling experiment data, (Table 2, row 3) where five of the six deuterium atoms on the molecule are retained and only one is lost in forming the $Y_{1}$ ion, at least one sulfate must be protonated on the reducing end, and the carboxylic acid group on the non-reducing end is most likely deprotonated.

The facile loss of sulfate upon CID provides an additional diagnostic ion amongst the three isomers. This was present reproducibly (at $15 \%$ relative abun-
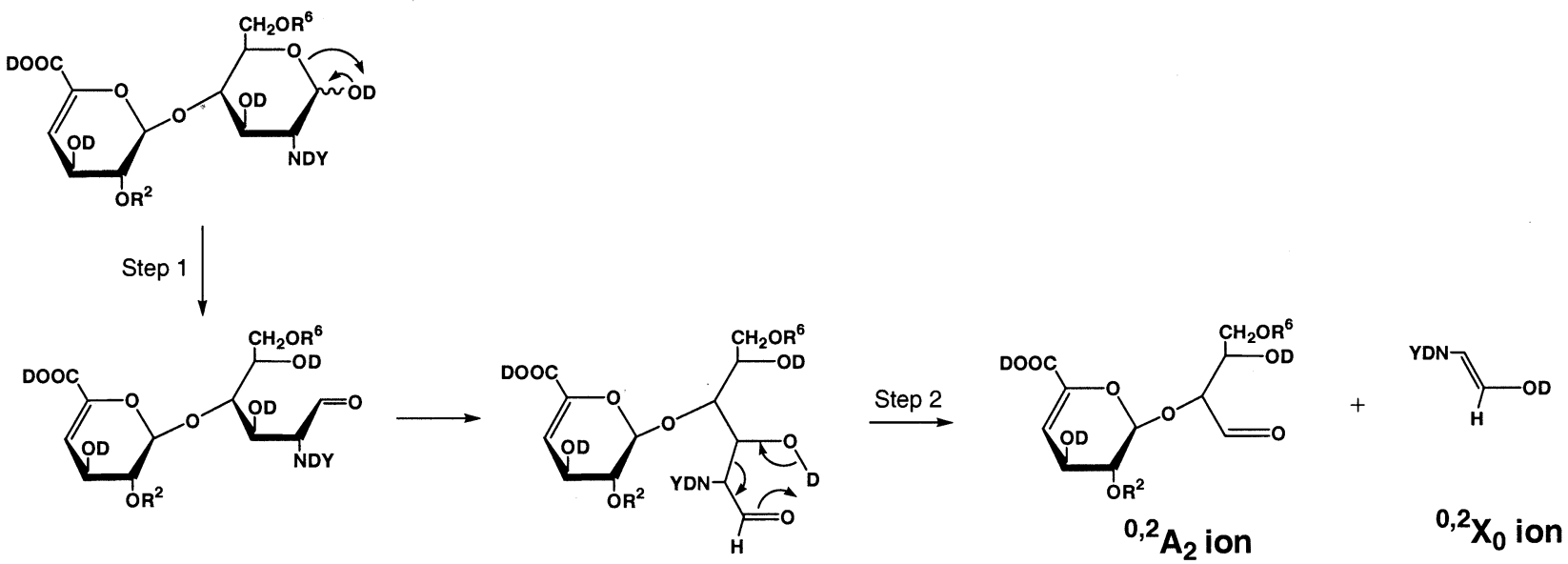

Scheme 4. Dissociation mechanism for formation of ${ }^{0,2} \mathrm{~A}_{2}$ and ${ }^{0,2} \mathrm{X}_{0}$ ions. 


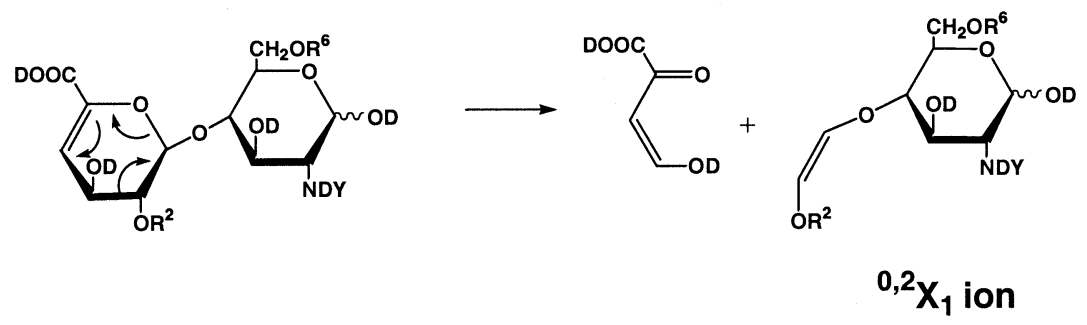

Scheme 5. Dissociation mechanism for formation of ${ }^{0,2} \mathrm{X}_{1}$ ions.

dance) for only disaccharide IIIS (Figure $4 b$ ), and for disaccharide IH to a small extent $(<5 \%$ relative abundance) (Figure 4c) as evidenced by the ion at $\mathrm{m} / \mathrm{z} 97$ $\left(\mathrm{HSO}_{4}^{-}\right.$). The complementary product ion at $\mathrm{m} / \mathrm{z} 398$ was only observed for disaccharide IIIS (Figure $4 \mathrm{~b}$ ). No sulfate loss was observed for IIS (Figure 4a). This may indicate that the facile loss of sulfate from the precursor may be coming from the 2-O-sulfate on the uronic acid, since that is the common feature for IIIS and IH.

\section{IIH/IIIH/IVS Heparin Disaccharides}

The monosulfated disaccharides IIH,IIIH and IVS were the final set of isomers studied. Under the spray conditions utilized the molecular ion for each disaccharide is observed at $\mathrm{m} / \mathrm{z} 416.1$ (Figure 2). The CID spectra for each of the three isomeric disaccharides are shown in Figure $5 \mathrm{a}-\mathrm{c}$ and each MS/MS spectrum provides a dissociation fingerprint unique for its corresponding

Table 1. Isotopic labeling results for IIA/ IIIA

\begin{tabular}{|c|c|c|c|c|c|c|c|}
\hline Labeling study & Precursor ion & Product ion & Mass loss (Da) & $\begin{array}{l}\text { Label present } \\
\text { in loss }\end{array}$ & $\begin{array}{c}\text { Dissociation product/ } \\
\text { origin of loss }\end{array}$ & $\| A$ & IIIA \\
\hline No label & $m / z 458$ & $\mathrm{~m} / \mathrm{z} 440$ & & & & & \\
\hline${ }^{18} \mathrm{O}$ & 460 & 442 & 18 & No ${ }^{18} \mathrm{O}$ & loss of $\mathrm{H}_{2} \mathrm{O}$ & $x$ & $x$ \\
\hline \multirow[t]{34}{*}{${ }^{2} \mathrm{H}$} & 464 & 445 & 19 & $1^{2} \mathrm{H}$ & & & \\
\hline & & $m / z 414$ & 44 & & & & \\
\hline & & 416 & 44 & No ${ }^{18} \mathrm{O}$ & loss of $\mathrm{CO}_{2}$ & & $x$ \\
\hline & & 420 & 44 & $\mathrm{No}{ }^{2} \mathrm{H}$ & & & \\
\hline & & $\mathrm{m} / \mathrm{z} 396$ & 62 & & & & \\
\hline & & 398 & 62 & No ${ }^{18} \mathrm{O}$ & loss of $\mathrm{CO}_{2} / \mathrm{H}_{2} \mathrm{O}$ & $x$ & $x$ \\
\hline & & 400 & 64 & $2{ }^{2} \mathrm{H}$ & & & \\
\hline & & $\mathrm{m} / \mathrm{z} \mathbf{3 7 8}$ & 80 & & & & \\
\hline & & 380 & 80 & $\mathrm{No}^{18} \mathrm{O}$ & loss of $\mathrm{SO}_{3}$ & $x$ & $x$ \\
\hline & & 384 & 80 & No ${ }^{2} \mathrm{H}$ & & & \\
\hline & & $\mathrm{m} / \mathrm{z} 360$ & 98 & & & & \\
\hline & & 362 & 98 & No ${ }^{18} \mathrm{O}$ & loss of $-\mathrm{SO}_{3} / \mathrm{H}_{2} \mathrm{O}$ & $x$ & $\mathrm{X}$ \\
\hline & & 364 & 100 & $2{ }^{2} \mathrm{H}$ & & & \\
\hline & & $\mathrm{m} / \mathrm{z} 357$ & 101 & & & & \\
\hline & & 357 & 103 & ${ }^{18} \mathrm{O}$ & ${ }^{0,2} A_{2}$ ion & $x$ & $x$ \\
\hline & & 361 & 103 & $2{ }^{2} \mathrm{H}$ & & & \\
\hline & & $m / z 342$ & 116 & & & & \\
\hline & & 344 & 116 & No ${ }^{18} \mathrm{O}$ & ${ }^{0,2} \mathrm{X}_{1}$ ion & $\mathrm{X}$ & $x$ \\
\hline & & 346 & 118 & $2{ }^{2} \mathrm{H}$ & & & \\
\hline & & $\mathrm{m} / \mathrm{z} \mathbf{3 0 0}$ & 158 & & & & \\
\hline & & 302 & 158 & No ${ }^{18} \mathrm{O}$ & $Y_{1}$ ion $(I I A)$ & $x$ & $x$ \\
\hline & & 304 & 160 & $2{ }^{2} \mathrm{H}$ & & & \\
\hline & & $\mathrm{m} / \mathrm{z} 282$ & 176 & & & & \\
\hline & & 284 & 176 & No ${ }^{18} \mathrm{O}$ & $\mathrm{Y}_{1}-\mathrm{H}_{2} \mathrm{O}$ ion (IIA) & $x$ & \\
\hline & & 286 & 178 & $2{ }^{2} \mathrm{H}$ & & & \\
\hline & & $m / z 237$ & 221 & & & & \\
\hline & & 237 & 223 & ${ }^{18} \mathrm{O}$ & $\mathrm{B}_{1}(\mathrm{IIIA})$ & & $\mathrm{X}$ \\
\hline & & 238 & 226 & $5{ }^{2} \mathrm{H}$ & & & \\
\hline & & $\mathrm{m} / \mathrm{z} 199$ & 259 & & & & \\
\hline & & 199 & 261 & ${ }^{18} \mathrm{O}$ & $Y_{1} /{ }^{0,2} A_{2}$ ion & $x$ & \\
\hline & & 201 & 263 & $4{ }^{2} \mathrm{H}$ & & & \\
\hline & & $\mathrm{m} / \mathrm{z} 157$ & 301 & & & & \\
\hline & & 157 & 303 & ${ }^{18} \mathrm{O}$ & $\mathrm{B}_{1}-\mathrm{SO}_{3}$ & & $x$ \\
\hline & & 158 & 306 & $5{ }^{2} \mathrm{H}$ & & & \\
\hline
\end{tabular}


Table 2. Isotopic labeling results for IIS/IIIS/IH for selected ions

\begin{tabular}{|c|c|c|c|c|c|c|c|c|}
\hline Labeling study & Precursor ion & Product ion(s) & Mass loss (Da) & $\begin{array}{l}\text { Label } \\
\text { present in } \\
\text { loss }\end{array}$ & $\begin{array}{l}\text { Dissociation product/ } \\
\text { origin of loss }\end{array}$ & IIS & IIIS & $\mathrm{IH}$ \\
\hline No label & $\mathrm{m} / \mathrm{z} 247.7^{2-}$ & $\mathrm{m} / \mathrm{z}$ 398, 97 & 97 & & & & & \\
\hline${ }^{18} \mathrm{O}$ & $248.7^{2-}$ & 400,97 & 97 & No ${ }^{18} \mathrm{O}$ & loss of $\mathrm{HSO}_{4}^{-}$ & & $X$ & \\
\hline \multirow[t]{37}{*}{${ }^{2} \mathrm{H}$} & $250.7^{2-}$ & 404, 97 & 97 & No ${ }^{2} \mathrm{H}$ & & & & \\
\hline & & $m / z 357$ & 138 & & & & & \\
\hline & & 357 & 140 & ${ }^{18} \mathrm{O}$ & ${ }^{0,2} A_{2}$ ion (IIS, IIIS) & $X$ & $X$ & \\
\hline & & 361 & 140 & $2{ }^{2} \mathrm{H}$ & & & & \\
\hline & & $m / z 338$ & 157 & & & & & \\
\hline & & 340 & 157 & No ${ }^{18} \mathrm{O}$ & $\mathrm{Y}_{1}{ }^{1-}$ ion (IIS) & $\mathrm{X}$ & & \\
\hline & & 343 & 158 & $1^{2} \mathrm{H}$ & & & & \\
\hline & & $m / z \mathbf{3 0 0}$ & 195 & & & & & \\
\hline & & 302 & 195 & No ${ }^{18} \mathrm{O}$ & ${ }^{0,2} \mathrm{X}_{1}-\mathrm{SO}_{3}$ ion & $\mathrm{X}$ & $X$ & \\
\hline & & 305 & 196 & $1^{2} \mathrm{H}$ & & & & \\
\hline & & $m / z 258$ & 237 & & $\mathrm{Y}_{1}(\mathrm{IIIS}, \mathrm{IH})$ & & & \\
\hline & & 260 & 237 & No ${ }^{18} \mathrm{O}$ & $\mathrm{Y}_{1}-\mathrm{SO}_{3}(\mathrm{IIS})$ & $X$ & $X$ & $\mathrm{X}$ \\
\hline & & 262 & 239 & $2{ }^{2} \mathrm{H}$ & & & & \\
\hline & & $m / z 255$ & 240 & & & & & \\
\hline & & 255 & 242 & ${ }^{18} \mathrm{O}$ & $C_{1}$ ion & & $\mathrm{X}$ & $\mathrm{x}$ \\
\hline & & 257 & 244 & $4{ }^{2} \mathrm{H}$ & & & & \\
\hline & & $m / z 237$ & 258 & & & & & \\
\hline & & 237 & 260 & ${ }^{18} \mathrm{O}$ & $\mathrm{B}_{1}$ ion $(\mathrm{IIIS}, \mathrm{IH})$ & & $X$ & $x$ \\
\hline & & 238 & 263 & $5{ }^{2} \mathrm{H}$ & & & & \\
\hline & & $m / z 218.0^{2-}$ & 59 & & & & & \\
\hline & & $218.0^{2-}$ & 61 & ${ }^{18} \mathrm{O}$ & ${ }^{0,2} \mathrm{~A}_{2}$ ion $(\mathrm{IH})$ & & & $x$ \\
\hline & & $219.6^{2-}$ & 62 & $3^{2} \mathrm{H}$ & & & & \\
\hline & & $m / z 189.6^{2-}$ & 116 & & & & & \\
\hline & & $190.6^{2-}$ & 116 & No ${ }^{18} \mathrm{O}$ & ${ }^{0,2} \mathrm{X}_{1}{ }^{2-}$ ion (IIS, IIIS) & $X$ & $\mathrm{X}$ & \\
\hline & & $191.6^{2-}$ & 118 & $2{ }^{2} \mathrm{H}$ & & & & \\
\hline & & $m / z 168.6^{2-}$ & 158 & & & & & \\
\hline & & $169.6^{2-}$ & 158 & No ${ }^{18} \mathrm{O}$ & $\mathrm{Y}_{1}^{2-}$ ion (IIS) & $X$ & & \\
\hline & & $170.6^{2-}$ & 160 & $2{ }^{2} \mathrm{H}$ & & & & \\
\hline & & $m / z 157$ & 338 & & $\mathrm{~B}_{1}(\mathrm{IIS})$ & & & \\
\hline & & 157 & 340 & ${ }^{18} \mathrm{O}$ & $\mathrm{B}_{1}-\mathrm{SO}_{3}$ (IIIS) & $x$ & $\mathrm{x}$ & \\
\hline & & 158 & 343 & $5{ }^{2} \mathrm{H}$ & & & & \\
\hline & & $\mathrm{m} / \mathrm{z} 138$ & 357 & & & & & \\
\hline & & 138 & 359 & ${ }^{18} \mathrm{O}$ & ${ }^{0,2} X_{0}$ ion (IIS, IIIS) & $\mathrm{X}$ & $x$ & \\
\hline & & 140 & 361 & $4{ }^{2} \mathrm{H}$ & & & & \\
\hline & & $m / z 115$ & 380 & & & & & \\
\hline & & 115 & 382 & ${ }^{18} \mathrm{O}$ & ${ }^{0,2} A_{1}$ ion (IIS) & $x$ & & \\
\hline & & 116 & 385 & $5{ }^{2} \mathrm{H}$ & & & & \\
\hline
\end{tabular}

disaccharide. Similar to the disulfated disaccharides, the most abundant product ion in each spectrum is a cross-ring cleavage, releasing the $\mathrm{C} 1-\mathrm{C} 2$ portion of the reducing-ring. In the case of disaccharides $\mathrm{IIH}$ and $\mathrm{IIIH}$ the one sulfate on the molecule is either on the 6-O position of the glucosamine or on the 2-O-position of the uronic acid, respectively, and in both instances it remains on the non-reducing side of the cleavage, thereby retaining the charge and forming the observed ${ }^{0,2} \mathrm{~A}_{2}$ ion. For disaccharide IVS, the same cleavage is observed, however the one sulfate group on the molecule is found on the reducing-end, at the 2-amino position of the glucosamine. Therefore if we consider that charge is retained on this sulfate, then the product ion observed is not an ${ }^{0,2} \mathrm{~A}_{2}$ ion, but the complementary ${ }^{0,2} X_{0}$ ion. Also common to all three disaccharides is the minimal loss of water from the precursor ion, and a small contribution from another cross-ring cleavage of the non-reducing ring, generating an ${ }^{0,2} X_{1}$ ion.
Regarding the distinguishing product ions, clearly for disaccharide IVS the abundant ${ }^{0,2} \mathbf{X}_{0}$ ion at $m / z 138$ is unique to this isomer and is predictably absent from the product ion spectra of disaccharides IIH and IIIH. For disaccharides IIH and IVS the sulfate group is located on the reducing ring, and predictably the product ions seen that correspond to glycosidic cleavages are $\mathrm{Y}$ and $\mathrm{Z}$ ions, where charge is probably retained on the sulfate group (Schemes 2 and 3). For disaccharide IIIH, however, the sulfate is on the non-reducing end uronic acid moiety and the product ions corresponding to glycosidic cleavage result in generation of $B_{1}$ ions. These product ions provide the diagnostic markers for disaccharides IIH and IIIH. The product ion at $\mathrm{m} / \mathrm{z} 258$ (Figure 5a) corresponds to a $\mathrm{Y}_{1}$ ion retaining the sulfate on the 6-O position upon CID of disaccharide $\mathrm{IIH}$, and is absent from the MS/MS spectra for disaccharides IIIH and IVS. Disaccharide IIIH, similar to IIIA and IIIS, contains a 2-O-sulfate on the uronic acid moiety, and 
Table 3. Isotopic labeling results for IIH/IIIH/IVS

\begin{tabular}{|c|c|c|c|c|c|c|c|c|}
\hline Labeling study & $\begin{array}{l}\text { Precursor } \\
\text { ion }\end{array}$ & Product ion & Mass loss (Da) & $\begin{array}{l}\text { Label present } \\
\text { in loss }\end{array}$ & $\begin{array}{c}\text { Dissociation } \\
\text { product/origin of } \\
\text { loss }\end{array}$ & $\mathrm{IIH}$ & $\mathrm{IIIH}$ & IVS \\
\hline No label & $\mathrm{m} / \mathrm{z} 416$ & $m / z 398$ & 18 & & & & & \\
\hline${ }^{18} \mathrm{O}$ & 418 & 400 & 18 & No ${ }^{18} \mathrm{O}$ & loss of $\mathrm{H}_{2} \mathrm{O}$ & $x$ & $x$ & $x$ \\
\hline \multirow[t]{31}{*}{${ }^{2} \mathrm{H}$} & 423 & 404 & 19 & $1{ }^{2} \mathrm{H}$ & & & & \\
\hline & & $m / z 357$ & 59 & & & & & \\
\hline & & 357 & 61 & ${ }^{18} \mathrm{O}$ & ${ }^{0,2} \mathrm{~A}_{2}$ ion $(\mathrm{IIH}, \mathrm{IIIH})$ & $x$ & $x$ & \\
\hline & & 461 & 62 & $3{ }^{2} \mathrm{H}$ & & & & \\
\hline & & $m / z 336$ & 80 & & & & & \\
\hline & & 338 & 80 & No ${ }^{18} \mathrm{O}$ & loss of $\mathrm{SO}_{3}$ & & & $x$ \\
\hline & & 343 & 80 & $\mathrm{No}^{2} \mathrm{H}$ & & & & \\
\hline & & $\mathrm{m} / \mathrm{z} \mathbf{3 0 0}$ & 116 & & & & & \\
\hline & & 302 & 116 & No ${ }^{18} \mathrm{O}$ & ${ }^{0,2} X_{1}$ ion & $X$ & $x$ & $\mathrm{X}$ \\
\hline & & 305 & 118 & $2{ }^{2} \mathrm{H}$ & & & & \\
\hline & & $\mathrm{m} / \mathrm{z} 258$ & 158 & & & & & \\
\hline & & 260 & 158 & No ${ }^{18} \mathrm{O}$ & $Y_{1}$ ion & $x$ & & \\
\hline & & 263 & 160 & $2{ }^{2} \mathrm{H}$ & & & & \\
\hline & & $m / z 240$ & 176 & & & & & \\
\hline & & 242 & 176 & No ${ }^{18} \mathrm{O}$ & $Z_{1}$ ion & $x$ & & $\mathrm{X}$ \\
\hline & & 244 & 179 & $3{ }^{2} \mathrm{H}$ & & & & \\
\hline & & $m / z 237$ & 179 & & & & & \\
\hline & & 237 & 181 & ${ }^{18} \mathrm{O}$ & $\mathrm{B}_{1}$ ion & & $x$ & \\
\hline & & 238 & 185 & $6{ }^{2} \mathrm{H}$ & & & & \\
\hline & & $m / z 222$ & 194 & & & & & \\
\hline & & 224 & 194 & ${ }^{18} \mathrm{O}$ & $\mathrm{Z}_{1}-\mathrm{H}_{2} \mathrm{O}(\mathrm{IVS}, \mathrm{IIH})$ & $x$ & & $x$ \\
\hline & & 224 & 199 & $5{ }^{2} \mathrm{H}$ & & & & \\
\hline & & $m / z 199$ & 217 & & & & & \\
\hline & & 199 & 219 & ${ }^{18} \mathrm{O}$ & $\mathrm{Y}_{1} /{ }^{0,2} \mathrm{~A}_{2}$ ion & $x$ & & \\
\hline & & 201 & 222 & $5^{2} \mathrm{H}$ & & & & \\
\hline & & $\mathrm{m} / \mathrm{z} 157$ & 259 & & & & & \\
\hline & & 157 & 261 & ${ }^{18} \mathrm{O}$ & $\mathrm{B}_{1}-\mathrm{SO}_{3}$ & & $x$ & \\
\hline & & 158 & 265 & $6{ }^{2} \mathrm{H}$ & & & & \\
\hline & & $\mathrm{m} / \mathrm{z} 138$ & 278 & & & & & \\
\hline & & 140 & 278 & No ${ }^{18} \mathrm{O}$ & ${ }^{0,2} \mathrm{X}_{0}$ ion (IVS) & & & $x$ \\
\hline & & 140 & 283 & $5^{2} \mathrm{H}$ & & & & \\
\hline
\end{tabular}

glycosidic cleavage of the precursor ion results in the formation of $\mathrm{B}_{1}$ and $\mathrm{B}_{1}-\mathrm{SO}_{3}$ ions at $m / z 237$ and $m / z 157$, respectively. The postulated mechanism for formation of this $B_{1}$ ion is also the same as that for disaccharides IIIS and IIIA (Scheme 1). The mechanism is again consistent with data from the ${ }^{2} \mathrm{H}$-labeling experiment (Table 3, row 7), because only one deuterium is retained upon formation of the $\boldsymbol{B}_{1}$ ion $(\mathrm{m} / z 238)$. The $\boldsymbol{B}_{1}$ product ion at $m / z 237$ for IIIH is unique to that isomer and can thus be used for identification and quantification in further studies.

Labeling Studies and Mechanisms of ${ }^{0,2} A_{2}$ and ${ }^{0,2} X_{1}$ Ion Formation

As evident from the data presented thus far, the product ions generated in the CID spectra of all eight heparin disaccharides correspond to either a loss of a neutral molecule, glycosidic cleavage (forming B, C, Y, and $\mathrm{Z}$ ions) or cross-ring cleavage (forming $\mathrm{X}$ and $\mathrm{A}$ ions). Since the disaccharide framework $(\Delta \mathrm{UA}-\beta(1,4)$ GlcNY) is the same for all eight of the heparin disaccharides studied here, it is not unreasonable to assume that there are several common dissociation pathways that are observed for all of the disaccharides. For example, the most apparent similarity amongst the CID spectra of all eight of the disaccharides is the presence of two main cross-ring cleavages resulting in formation of both ${ }^{0,2} \mathrm{~A}_{2}$ and ${ }^{0,2} \mathrm{X}_{1}$ ions.

From analysis of all of the labeling data presented, the loss of the $\mathrm{C} 1-\mathrm{C} 2$ carbons of the reducing ring, to form the ${ }^{0,2} \mathrm{~A}_{2}$ ion, is consistent for all eight disaccharides (Tables 1-3). For example, for disaccharides IIA/ IIIA $(m / z 458)$ the product ion at $m / z 357$ is formed from a $101 \mathrm{Da}$ loss. Since the mass of the neutral that was lost is odd, it is assumed that the nitrogen and C2 are included in the lost neutral molecule. Furthermore, when the ${ }^{18} \mathrm{O}$-labeled disaccharides of interest $(\mathrm{m} / \mathrm{z} 460)$ are subjected to CID, they produce product ions $(\mathrm{m} / \mathrm{z}$ 357) that do not retain the label, thus indicating the loss of the C1-oxygen and $\mathrm{C} 1$ as well. A combination of these data with that from the ${ }^{2} \mathrm{H}$-labeling experiment indicating that two exchangeable protons are also included in the loss, points towards the assignment of the product ion at $m / z 357$ as the ${ }^{0,2} \mathrm{~A}_{2}$ ion (Table 1, row 6).

To generate the ${ }^{0,2} \mathrm{~A}_{2}$ ion requires the breaking of two 

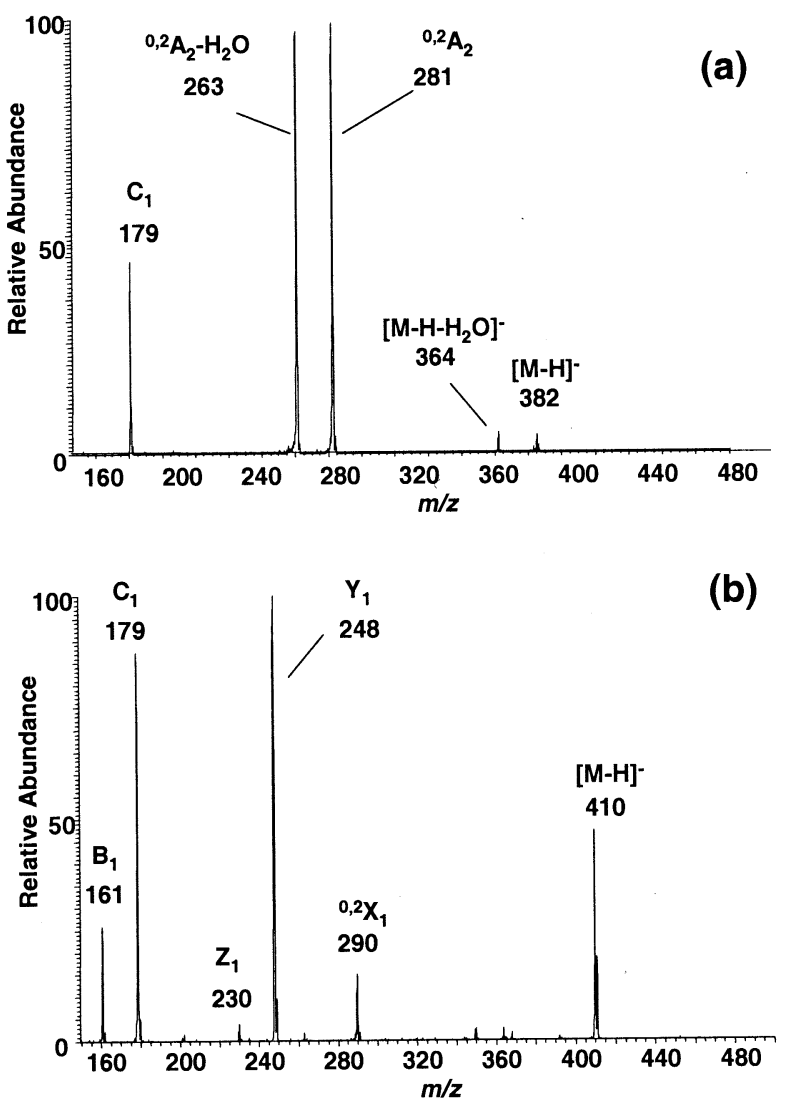

Figure 6. Negative ion $\mathrm{MS}^{2}$ spectra of (a) $\mathrm{N}$-acetyllactosamine. Ion activation at $0.50 \mathrm{~V}, 20 \%$ normalized collision energy for 100 ms; (b) $N$-acetyllactosamine, $\beta$-ethyl glycoside. Ion activation at $26 \%$ normalized collision energy, $0.67 \mathrm{~V}$, for $100 \mathrm{~ms}$.

bonds on the reducing ring; the $\mathrm{C} 1-\mathrm{O}$ (ring) and the C2-C3 bonds. Since simultaneous breaking of two bonds may not be energetically favorable, we suggest a stepwise mechanism as shown in Scheme 4. The first step appears to be opening of the reducing ring during CID to form the acyclic hydroxy aldehyde species (Step 1 , Scheme 4). This ring-opening step has also been proposed previously by Leary et al. in the study of isomeric lithium-cationized disaccharide fragmentation [18], and by Mulroney et al. in the study of glucopyranosyl disaccharide fragmentation by using molecular orbital calculations [16] and others [19]. This postulated first step is also supported by CID data obtained from $N$-acetyllactosamine and its $\beta$-ethyl glycoside derivative (Figure $6 \mathrm{a}$ and $\mathrm{b}$ ). Upon collisional activation of $\mathrm{N}$-acetyllactosamine $(0.50 \mathrm{~V}, 20 \%$ normalized collison energy) the predominant product ions formed result from a cross-ring cleavage; specifically, the formation of the ${ }^{0,2} \mathrm{~A}_{2}$ ion, the same observation for the heparin disaccharides (Figure 6a). The $\mathrm{N}$-acetyllactosamine $\beta$-ethyl glycoside derivative, however, was different. First, MS/MS under similar collision conditions (i.e., $0.51 \mathrm{~V}, 20 \%$ normalized collision energy) produced no observable dissociation of the isolated precursor ion at $\mathrm{m} / \mathrm{z} 410$ (data not shown). Only upon increasing the collision energy $(0.67 \mathrm{~V}, 26 \%$ normalized collision energy) was dissociation observed, and the precursor ion depleted by $50 \%$ (Figure $6 \mathrm{~b}$ ). The need for additional energy to produce any fragmentation of the glycoside attests to its relative greater stability to dissociation. Furthermore, with the increased energy provided, the dissociation pathways that the glycoside was directed to undergo were mostly glycosidic cleavages in this case (Figure 6b). Since the anomeric oxygen is protected as the $\beta$-ethyl glycoside, this prevents the necessary ring-opening step, thereby precluding the formation of product ions such as the ${ }^{0,2} \mathrm{~A}_{2}$ ion by reducing-ring cleavage as proposed in our mechanism (Scheme 4). Instead, the main product ions formed are due to the glycosidic cleavages and one other cross-ring cleavage to produce the ${ }^{0,2} X_{1}$ ion.

According to our proposed mechanism (Step 2, Scheme 4) another requirement is the available hydrogen atom on the $\mathrm{C} 3$ hydroxy group. This mechanism is supported by the deuterium-labeling experiments, which indicate that a deuterium and not hydrogen (from C4) is transferred to the carbonyl group in the two-carbon fragmentation. To further illustrate this, another glycosaminoglycan disaccharide, was used. Chondroitin disaccharide, $\Delta \mathrm{UA}-$ GalNAc6S, is most similar to disaccharide IIA among the heparin disaccharides but contains a $\beta(1,3)$-linkage between the uronic acid and hexosamine residue, instead of the $\beta(1-4)$ linkage found in heparin, and a galactosamine residue at the reducing end instead of glucosamine. Consistent with our hypothesis, this disaccharide shows no formation of a ${ }^{0,2} \mathrm{~A}_{2}$ ion, even with the possibility of forming an open-ring structure. Instead, the product ions formed were mainly due to glycosidic cleavages and a small contribution from the cross-ring cleavage generating a ${ }^{0,2} \mathrm{X}_{1}$ ion. No abstraction of the $\mathrm{C} 4$ hydrogen is seen as transferred to the carbonyl for $\mathrm{C} 1-\mathrm{C} 2$ loss (Figure 7).

The second common product ion formed among the heparin disaccharides is the ${ }^{0,2} X_{1}$ ion. From analysis of all of the labeling data for each of the disaccharides, formation of this ion is consistent with the loss of the C3-C6 carbons of the non-reducing ring (Tables 1-3). For example, for disaccharides IIH/IIIH/IVS $(\mathrm{m} / \mathrm{z} 416)$ the product ion at $\mathrm{m} / \mathrm{z} 300$ is formed from a 116 Da loss. Since the mass of the neutral that was lost is even, it is assumed that the nitrogen and $\mathrm{C} 2$ are not part of the loss. Furthermore, when the ${ }^{18} \mathrm{O}-$ labeled disaccharides of interest $(\mathrm{m} / \mathrm{z} 418)$, are subjected to CID they produce product ions $(\mathrm{m} / \mathrm{z} 302)$, which retain the label, thus indicating that the $\mathrm{C} 1$-oxygen and $\mathrm{C} 1$ are retained in the product ion. A combination of these data with that from the ${ }^{2} \mathrm{H}$-labeling experiment indicating that two exchangeable protons are also included in the loss, points towards the assignment of the product ion at $\mathrm{m} / \mathrm{z} 300$ as the ${ }^{0,2} X_{1}$ ion (Table 3, row 4).

To generate the ${ }^{0,2} X_{1}$ ion requires the breaking of two bonds on the non-reducing ring; the $\mathrm{C} 1-\mathrm{O}$ (ring) and the $\mathrm{C} 2-\mathrm{C} 3$ bonds. The mechanism proposed in Scheme 5 is 
(a)

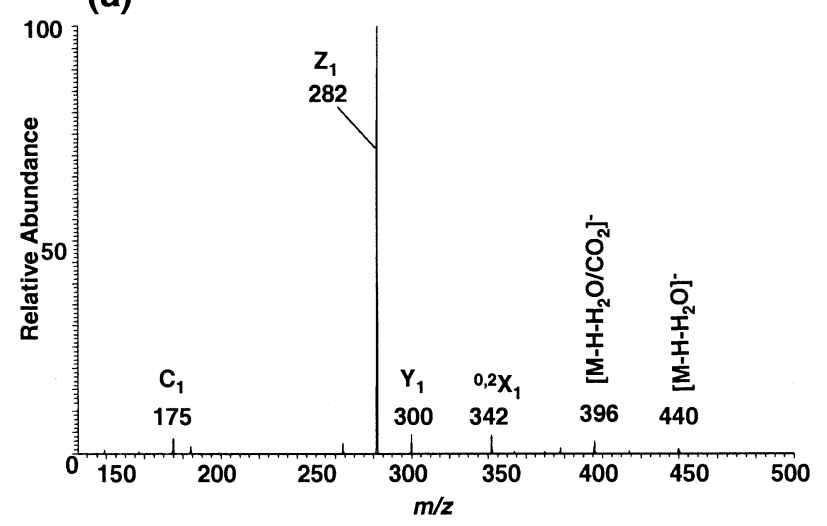

(b)
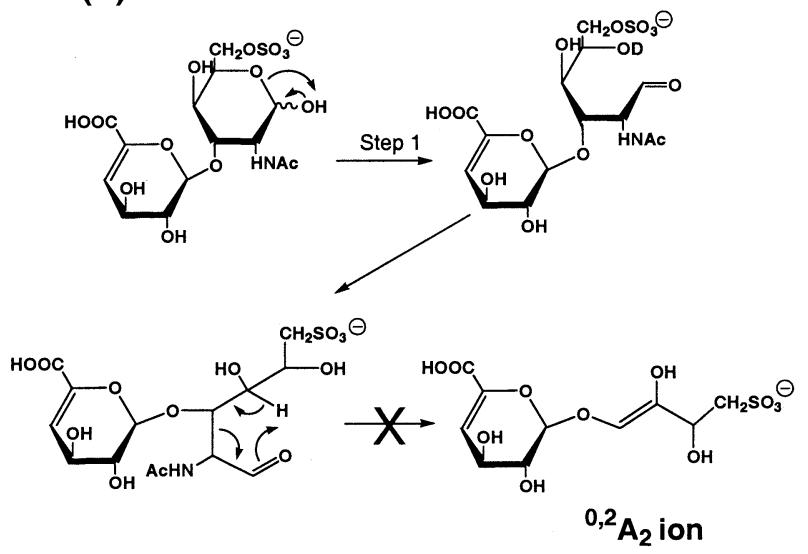

Figure 7. Negative polarity CID MS/MS spectrum for chondroitin sulfate disaccharide $\triangle \mathrm{UA}$-GalNAc6S. Collision energy was set to $29 \%$ normalized collision energy, $0.79 \mathrm{~V}$.

a concerted reverse-Hetero-Diels-Alder reaction to generate the product ions. The diene in this case is the $\alpha, \beta$-unsaturated ketone. Whereas the normal DielsAlder reaction is favored by the presence of electronreleasing groups on the diene, in this example our diene possesses the electron-withdrawing carboxylic acid group, perhaps thus promoting the reverse reaction.

The mechanisms we have proposed for ${ }^{0,2} \mathrm{~A}_{2}$ ion and ${ }^{0,2} X_{1}$ ion formation in Schemes 4 and 5 are both chargeremote fragmentation pathways. Although charge-remote fragmentation is not as common as charge-driven or radical-driven processes, there is precedent from the literature, that any molecule with a stable charge site, such as sulfates, may undergo charge-remote processes [20]. To induce these charge-remote fragmentations, the site of charge must be stable so that it is not involved in the fragmenting portion of the ion. The process was first extensively studied with unsaturated fatty acids and their derivatives by Gross et al. [21]. Other examples include anionic surfactants containing a sulfate polar head group [22] as well as more rigid steroid conjugates containing a sulfate group on the peripheral ring, with predominant fragmentation occurring at a distal reac- tion site [23]. Interestingly, there are not many examples of collision induced dissociation of carbohydrate ions, where charge-remote fragmentation mechanisms have been implicated. One such example involves CID of 2-aminopyridine derivatives of FAB-generated oligosaccharides, in which charge was retained on the pyridine moiety [24]. Another consideration, is that although charge-remote dissociations of ions are common under high-energy collisional activation (keV), some can also occur under low-energy collisional activation as has been initiated in quadrupole collision cells [25]. The energy requirement for charge-remote cleavage of a $\mathrm{C}-\mathrm{C}$ bond was also estimated, in work by Gross, on fragmentation of alkyl chains of fatty alcohols, as only between 1.3 and $1.9 \mathrm{eV}$, about one-half of the $\mathrm{C}-\mathrm{C}$ bond energy [26]. Our mechanism for the ${ }^{0,2} \mathrm{~A}_{2}$ ion formation also involves a six-electron, six-membered aromatic-like transition state, thus stabilizing the ensuing intermediate and the dissociation. Given the fact that this ion has been formed from all eight of the disaccharides with their variable sulfation patterns, it is likely that this ion may be produced via a charge-remote dissociation mechanism such as that postulated. Similarly we see formation of ${ }^{0,2} X_{1}$ ions in most cases for each of the heparin disaccharides, which we have also postulated is formed by another charge-remote dissociation pathway (Scheme 5).

\section{Conclusions}

The eight heparin disaccharides, isomeric with at least one other disaccharide were analyzed and differentiated by negative ionization tandem mass spectrometry. The MS/MS studies provided unique product ion spectra of each of the isomers, useful for identification and future quantification of the relative amounts of each isomer present. Isotopic labeling studies using ${ }^{18} \mathrm{O}$ and ${ }^{2} \mathrm{H}$ were used to determine the origins of each of the neutral molecules lost in the product ion spectra, and mechanisms of dissociation consistent with the observed data were postulated. The general mechanisms included were for generation of the typical glycosidic cleavages seen for the disaccharides (forming B, Y, C, and $\mathrm{Z}$ ions) as well as cross-ring cleavages (forming $\mathrm{A}$ and $X$ ions). Upon CID, disaccharides having a sulfate group on the non-reducing ring uronic acid (IIIA, IIIS and $\mathrm{IIIH})$, consistently formed $\mathrm{B}_{1}$ product ions and $\mathrm{B}_{1}-\mathrm{SO}_{3}$ ions. $\mathrm{Z}$ and $\mathrm{Y}$ ions were common to those disaccharides with 6-O sulfation and $N$-sulfation. Mechanisms for these glycosidic cleavages were postulated consistent with the data obtained from the ${ }^{18} \mathrm{O}$ and ${ }^{2} \mathrm{H}$-labeling experiments. All eight heparin disaccharides also underwent ${ }^{0,2} \mathrm{X}_{1}$ and ${ }^{0,2} \mathrm{~A}_{2}$ cross-ring cleavages. The observations of these cleavages independent of the polarity used for CID suggest that the mechanisms of their formation are through a charge-remote process. To our knowledge this is the first evidence presented in favor of charge-remote fragmentations of sulfated carbohydrates. 
In the presented work we have demonstrated the successful use of tandem mass spectrometry in the differentiation of all twelve known standard heparinbuilding blocks, including the potentially important $\mathrm{N}$-unsubstituted disaccharides. This information is important towards the determination of complete disaccharide compositions of heparin/HS. In addition we have postulated mechanisms of dissociation of these disaccharides upon CID, which can be further applied to the sequencing of larger heparin/HS oligosaccharides. Future work in our laboratory will focus on combining the information obtainable from tandem mass spectrometry of heparin/HS oligosaccharides with their disaccharide composition as determined by using previously established methods $[9,13]$. Together, this provides a practical methodology for the future analysis of heparin/HS oligosaccharides of unknown structure.

\section{Acknowledgments}

The authors gratefully acknowledge the NIH for funding this research (grant no. GM47356).

\section{References}

1. Capila, I.; Linhardt, R. J. Heparin-Protein Interactions. Angew. Chem. Int. Ed. 2002, 41(391), 412.

2. Falshaw, R.; Furneaux, R.; Slim, G. In Carbohydrates: Structures, Syntheses, and Dynamics; Finch, P., Ed.; Kluwer Academic: Dordrecht, The Netherlands, 1999; pp 107-149.

3. Norgardsumnicht, K.; Varki, A. Endothelial Heparan-Sulfate Proteoglycans That Bind to L-Selectin Have Glucosamine Residues with Unsubstituted Amino-Groups. J. Biol. Chem. 1995, 270, 12012-12024.

4. Koenig, A.; Norgard-Sumnicht, K.; Linhardt, R.; Varki, A. Differential Interactions of Heparin and Heparan Sulfate Glycosaminoglycans with the Selectins-Implications for the Use of Unfractionated and Low Molecular Weight Heparins as Therapeutic Agents. J. Clin. Invest. 1998, 101, 877-889.

5. Zamfir, A.; Seidler, D. G.; Kresse, H.; Peter-Katalinic, J. Structural Investigation of Chondroitin/Dermatan Sulfate Oligosaccharides from Human Skin Fibroblast Decorin. Glycobiology 2003, 13, 733-742.

6. Zamfir, A.; Seidler, D. G.; Kresse, H.; Peter-Katalinic, J. Structural Characterization of Chondroitin/Dermatan Sulfate Oligosaccharides from Bovine Aorta by Capillary Electrophoresis and Electrospray Ionization Quadrupole Time-of-Flight Tandem Mass Spectrometry. Rapid Commun. Mass Spectrom. 2002, 16, 2015-2024.

7. Zaia, J.; Costello, C. E. Tandem Mass Spectrometry of Sulfated Heparin-Like Glycosaminoglycan Oligosaccharides. Anal. Chem. 2003, 75, 2445-2455.

8. Zaia, J.; Li, X. Q.; Chan, S. Y.; Costello, C. E. Tandem Mass Spectrometric Strategies for Determination of Sulfation Positions and Uronic Acid Epimerization in Chondroitin Sulfate Oligosaccharides. J. Am. Soc. Mass Spectrom. 2003, 14, 12701281.

9. Saad, O. M.; Lim, A.; Thanawiroon, C.; Leary, J. A. Detection and Quantification of Twelve Heparin- and Heparan Sulfate-
Derived Disaccharides by Electrospray Ionization Ion Trap Tandem Mass Spectrometry: Application to Heparin/Heparan Sulfate Oligosaccharide Sequencing. Glycobiology 2003, 13, 842-842.

10. Desaire, H.; Sirich, T. L.; Leary, J. A. Evidence of Block and Randomly Sequenced Chondroitin Polysaccharides: Sequential Enzymatic Digestion and Quantification Using Ion Trap Tandem Mass Spectrometry. Anal. Chem. 2001, 73, 3513-3520.

11. Desaire, H.; Leary, J. A. Detection and Quantification of the Sulfated Disaccharides in Chondroitin Sulfate by Electrospray Tandem Mass Spectrometry. J. Am. Soc. Mass Spectrom. 2000, 11, 916-920.

12. Varki, A.; Cummings, R.; Esko, J.; Freeze, H.; Hart, G.; Marth, J. Essentials of Glycobiology, Cold Spring Harbor Laboratory Press, Cold Spring Harbor, NY, 1999.

13. Saad, O. M.; Leary, J. A. Compositional Analysis and Quantification of Heparin and Heparan Sulfate by Electrospray Ionization Ion Trap Mass Spectrometry. Anal. Chem. 2003, 75, 2985-2995.

14. Desai, U. R.; Wang, H. M.; Linhardt, R. J. Specificity Studies on the Heparin Lyases from Flavobacterium-Heparinum. Biochemistry 1993, 32, 8140-8145.

15. Domon, B.; Costello, C. E. A Systematic Nomenclature for Carbohydrate Fragmentations in FAB-MS MS Spectra of Glycoconjugates. Glycoconj. J. 1988, 5, 397-409.

16. Mulroney, B.; Peel, J. B.; Traeger, J. C. Theoretical Study of Deprotonated Glucopyranosyl Disaccharide Fragmentation. J. Mass Spectrom. 1999, 34, 856-871.

17. Mulroney, B.; Peel, J. B.; Traeger, J. C. Relative Gas-Phase Acidities of Glucopyranose from Molecular Orbital Calculations. J. Mass Spectrom. 1999, 34, 544-553.

18. Hofmeister, G. E.; Zhou, Z.; Leary, J. A. Linkage Position Determination in Lithium-Cationized Disaccharides-Tandem Mass-Spectrometry and Semiempirical Calculations. J. Am. Chem. Soc. 1991, 113, 5964-5970.

19. Carroll, J. A.; Willard, D.; Lebrilla, C. B. Energetics of CrossRing Cleavages and Their Relevance to the Linkage Determination of Oligosaccharides. Anal. Chim. Acta 1995, 307(431), 447.

20. Adams, J. Charge-Remote Fragmentations-Analytical Applications and Fundamental Studies. Mass Spectrom. Rev. 1990, 9, 141-186.

21. Tomer, K. B.; Crow, F. W.; Gross, M. L. Location of DoubleBond Position in Unsaturated Fatty-Acids by Negative-Ion MS/MS. J. Am. Chem. Soc. 1983, 105, 5487-5488.

22. Lyon, P. A.; Stebbings, W. L.; Crow, F. W.; Tomer, K. B.; Lippstreu, D. L.; Gross, M. L. Analysis of Anionic Surfactants by Mass-Spectrometry Mass-Spectrometry with Fast Atom Bombardment. Anal. Chem. 1984, 56, 8-13.

23. Tomer, K. B.; Jensen, N. J.; Gross, M. L.; Whitney, J. Fast-Atom Bombardment Combined with Tandem Mass-Spectrometry for Determination of Bile-Salts and Their Conjugates. Biomed. Environ. Mass 1986, 13, 265-272.

24. Carr, S. A.; Reinhold, V. N.; Green, B. N.; Hass, J. R. Enhancement of Structural Information in Fab Ionized Carbohydrate Samples by Neutral Gas Collision. Biomed. Mass Spectrom. 1985, 12, 288-295.

25. Whalen, K.; Grossert, J. S.; Boyd, R. K. Ion Dissociation Reactions Induced in a High-Pressure Quadrupole Collision Cell. Rapid Commun. Mass Spectrom. 1995, 9, 1366-1375.

26. Gross, M. L. Charge-Remote Fragmentation: An Account of Research on Mechanisms and Applications. Int. J. Mass Spectrom. 2000, 200, 611-624. 